\title{
The Role of Zyxin in Carcinogenesis
}

\author{
ALEKSANDRA PARTYNSKA ${ }^{1}$, AGNIESZKA GOMULKIEWICZ ${ }^{1}$, \\ PIOTR DZIEGIEL ${ }^{1,2}$ and MARZENNA PODHORSKA-OKOLOW ${ }^{3}$ \\ ${ }^{1}$ Department of Histology and Embryology, Department of Human Morphology and Embryology, \\ Faculty of Medicine, Wroclaw Medical University, Wroclaw, Poland; \\ ${ }^{2}$ Human Biology Unit, Faculty of Physiotherapy, \\ University School of Physical Education in Wroclaw, Wroclaw, Poland; \\ ${ }^{3}$ Department of Ultrastructural Research, Faculty of Medicine, Wroclaw Medical University, Wroclaw, Poland
}

\begin{abstract}
Zyxin (ZYX) is a LIM domain protein whose presence has been detected in the cytoplasm and nucleus. ZYX can translocate between these two compartments and therefore, can take part in the regulation of various cellular processes. VASP and $\alpha$-actinin are examples of proteins that interact with ZYX. As ZYX is present in focal adhesions (FAs), an immense part of research is focused on the role of this protein in the organisation and function of the cytoskeleton. Other studies aim to explain the impact of zyxin on other intracellular processes. Zyxin has been shown to take part in apoptosis, as well as in wound healing. Additionally, zyxin contribution to cancer development is gaining growing interest. This paper aims to systematise the knowledge on zyxin and its role in carcinogenesis.
\end{abstract}

Zyxin (ZYX) is classified as a LIM domain protein (1). LIM domain contains two cysteine and histidine-rich zinc finger motifs (sequence C- $\mathrm{X}_{2}-\mathrm{C}-\mathrm{X}_{17-19}-\mathrm{H}-\mathrm{X}_{2}-\mathrm{C}-\mathrm{X}_{2}-\mathrm{C}-\mathrm{X}_{2}-\mathrm{C}-\mathrm{X}_{15-19^{-}}$ C) $(2,3)$. ZYX can interact through these domains with other molecules and thus, regulate various intracellular processes (1). The name "LIM domain" comes from the proteins in which it was discovered for the first time: Lin-11, Isl1, and Mec-3 (2). Paxilin, TRIP6, testin, and LASP belong to the same large family of proteins (1). LIM domain proteins are involved in many intracellular processes, such as cytoskeleton

This article is freely accessible online.

Correspondence to: Aleksandra Partynska, Department of Histology and Embryology, Department of Human Morphology and Embryology, Wroclaw Medical University, T. Chalubinskiego 6a, 50-368 Wroclaw, Poland. Tel: +48 717841354, e-mail: ola.partynska@onet.pl

Key Words: Zyxin, LIM domain proteins, cancer, review. organisation, transcription regulation, cell differentiation, and oncogenesis (Figure 1) (2).

Gene encoding human ZYX is located on chromosome 7 (4, 5). Zyxin is a phosphorylated protein with a molecular mass of 82-84 $\mathrm{kDa}$ (6). This protein can be present not only in the cytoplasm, but also in the nucleus (2) (Figure 2), and the translocation between these two compartments can occur under various conditions (7), such as mechanical forces or EGF (epidermal growth factor) $(7,8) . \mathrm{ZYX}$ is a component of focal adhesions (FAs) responsible for the interaction between a cell and the extracellular matrix, and also takes part in the organisation and regeneration of the cytoskeleton (1). This protein is a pivotal component of stress fibres (SFs), i.e. contractile actomyosin fibres determining cell migration $(1,9)$. Zyxin is known as a mechanosensor - under mechanical forces it i) translocates into the nucleus where it can regulate gene expression, or ii) localises along stress fibres to take part in actin polymerisation (10-12). The structure of ZYX consists of sequences that enable the protein to perform its functions. These are: $\alpha$-actinin [i.e. protein crosslinking actin filaments (13)] binding site, 4 proline-rich repeats (so-called ActA repeats), and 2 leucine-rich nuclear export sequences (NES) (Figure 3) (1). ActA repeats, identified for the first time in ActA protein of Listeria monocytogenes bacterium $(14,15)$, are responsible for interaction with VASP (Vasodilator-stimulated phosphoprotein), which plays a role in actin polymerisation. In addition, three LIM domains (LIM1, LIM2, and LIM3) essential for ZYX targeting to focal adhesions and the cytoskeleton are located at the C-terminus (1). LIM domains allow zyxin to interact with other molecules, such as cell cycle and apoptosis regulator protein-1 (CARP-1) (16) or transcription factor ZNF384, involved in osteoblast differentiation (7).

Activity of ZYX might be regulated, inter alia, through its head-tail interactions $(17,18)$. These interactions are based on LIM domain binding to the proximity of prolinerich regions (ActA repeats) and the release of zyxin from 
binding with proteins (i.e. so-called closed conformation) $(17,18)$. Serine phosphorylation at position 142 (S142) was shown to be indispensable for the elimination of the ZYX head-tail interaction that recovers the ability to bind other proteins $(17,18)$.

The study of Guo and Wang (19), performed on a murine embryonic fibroblast cell line (NIH3T3), revealed that zyxin is transported retrogradely in the form of so-called "tails" from focal adhesions to the cell interior. This phenomenon was dependent on the stiffness of the substrate, on which cells were grown. In addition, the number of "tails" was negatively correlated with the speed of cell migration (19). Another study showed that mechanical stress resulted in zyxin translocation from focal adhesions to actin filaments (20). What is more, it turned out that zyxin was essential for VASP localisation along stress fibres in cells subjected to mechanical stress (20).

The contribution of zyxin to cellular processes has also been described in apoptosis. Experiments carried out on a murine embryonic fibroblast cell line (MEF) treated with UV-C radiation showed that zyxin promoted cell death (21). Translocation of zyxin from the cytoplasm into nucleus, as well as an increase in both caspase- 3 activity and the percentage of apoptotic cells (detected with TUNEL method) were detectable under UV-C radiation (21).

The study of Han et al. suggests that ZYX may play a role in wound healing (22). Zyxin was shown to influence von Willebrand factor secretion from murine endothelial cells (22). Knockout of Zyx in mice caused longer bleeding time after epinephrine stimulation, in comparison to wild type (WT) mice (22). Moreover, Zyx knockout negatively affected thrombus formation (22).

Numerous studies are focused on the role of ZYX as a component of focal adhesions and the cytoskeleton, and as a mechanosensor. It is commonly known that changes in the expression of cytoskeleton-organising proteins have an impact on cell migration, which is important in metastasis $(9,23)$. Not only for this reason, but also for its abovementioned features, the role of ZYX in carcinogenesis is getting much attention from researchers.

\section{The Role of Zyxin in Carcinogenesis}

The role of ZYX in oncogenesis is not clearly defined. The research carried out in recent years has confirmed the contribution of ZYX to the development of various cancer types, including melanoma, ovarian, breast, glioma, lung, and oral squamous cell carcinoma $(6,24-28)$. Recent observations have revealed that ZYX can act as an oncoprotein or a tumour suppressor, depending on the cancer type (16).

Breast cancer. Many studies have shown that ZYX can promote breast carcinogenesis. Increased level of ZYX was detected in radiotherapy-resistant (RR) breast cancer cell lines MCF-7RR and MDA-MB-231RR, in comparison to the sensitive ones (29). However, the studies of Hodgkinson et al. presented decreased ZYX expression in chemotherapyresistant breast tumours when compared to cancer cells that are sensitive to chemotherapy (30). These results suggest, that zyxin expression level may determine the sensitivity of cancer cells to a particular kind of anticancer therapy and may be helpful in predicting its effectiveness.

Ma et al. noticed that ZYX might act as an oncogene in breast cancer cells. It was shown that ZYX-silenced MDAMB-231 cells were characterised by decreased migration. Such cells injected into mice, formed tumours of smaller mass than controls (25). Furthermore, based on the results of immunohistochemical reactions (IHC) performed on breast tumours resected from patients, a positive correlation between zyxin level and cancer stage was demonstrated (25).

During further experiments explaining the mechanism of ZYX interactions in cancer cells, Ma et al. observed that this protein takes part in the regulation of Hippo signalling pathway (25). Activation of Hippo signalling pathway leads to cell growth and proliferation inhibition $(31,32)$. The direct reason for this phenomenon is Yes-associated protein (YAP) and Transcriptional co-activator with PDZ-binding motif (TAZ) phosphorylation by Large Tumour Suppressor $1 / 2$ (LATS 1/2) factor $(31,32)$. Such phosphorylation leads to protein accumulation and degradation in the cytoplasm, resulting in cell proliferation inhibition (31). The discussed studies showed that under hypoxic conditions and after TGF $\beta$ stimulation, ZYX forms a complex with LATS2 and Siah2 (E3 ubiquitin ligase, involved in LATS2 degradation), which leads to Hippo pathway deactivation (25) and cell proliferation. It is worth mentioning that YAP and TAZ proteins have an impact on the activity of TEAD and SMAD transcription factors, which are responsible, inter alia, for cell survival and growth (31). The results of these studies suggest that ZYX may play a role in the development and progression of breast cancer.

The contribution of ZYX to the regulation of Hippo signalling pathway is confirmed by Diepenbruck et al. (32). Their studies showed that zyxin expression in breast cancer cells is controlled by Tead 2 (transcription factor), and more specifically by Tead2-Taz complex (32). Tead2 overexpression in murine breast cancer cells resulted in increased cell invasion (32). Further analyses showed that cells characterised by Tead2 over-expression but with Zyx silencing, demonstrated significantly decreased invasion (32). According to earlier studies, YAP and TAZ proteins take part in the regulation of epithelial-mesenchymal transition (EMT) (33-35). It can thus be suggested that ZYX, together with these proteins, can also impact the EMT process and thus, influence breast cancer cell invasion. The study of Mori et al. seems to confirm this hypothesis, as they 


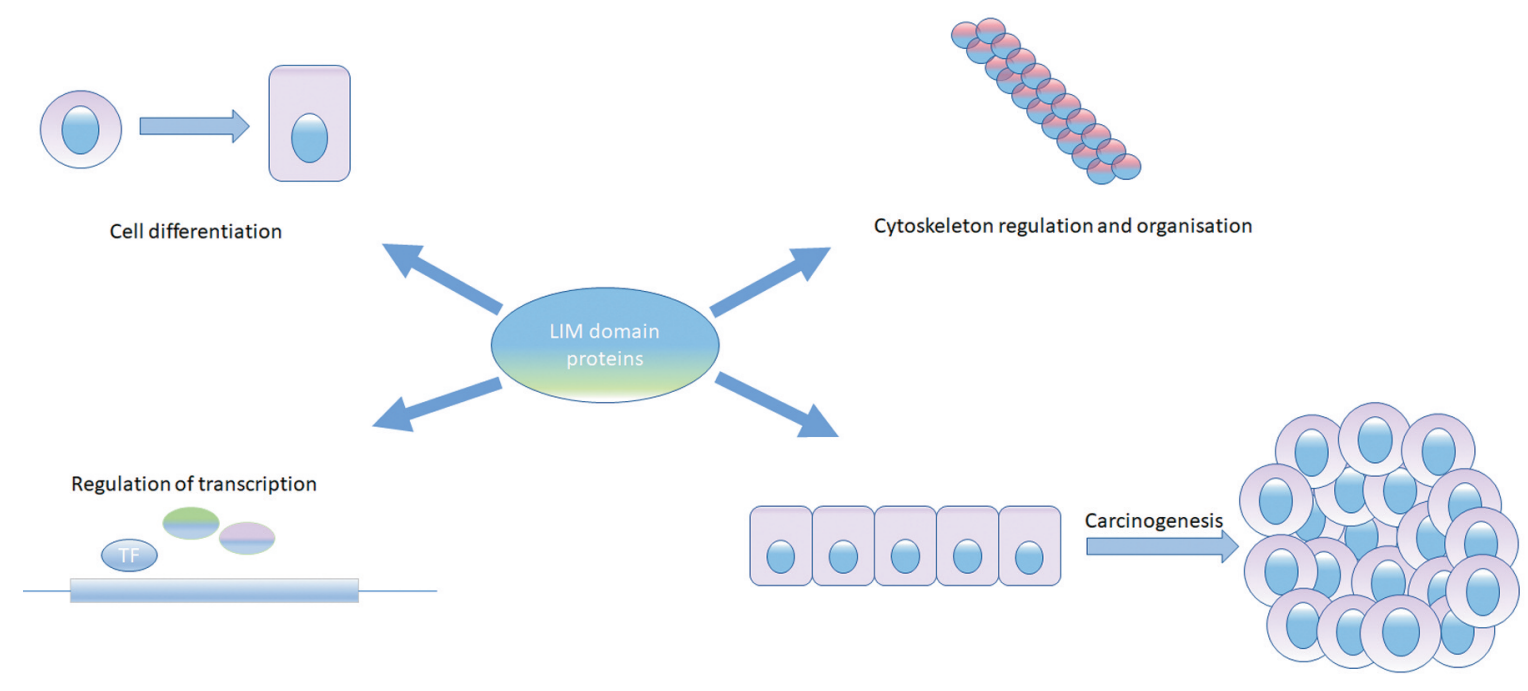

Figure 1. Exemplary functions of LIM domain proteins [based on (2)].

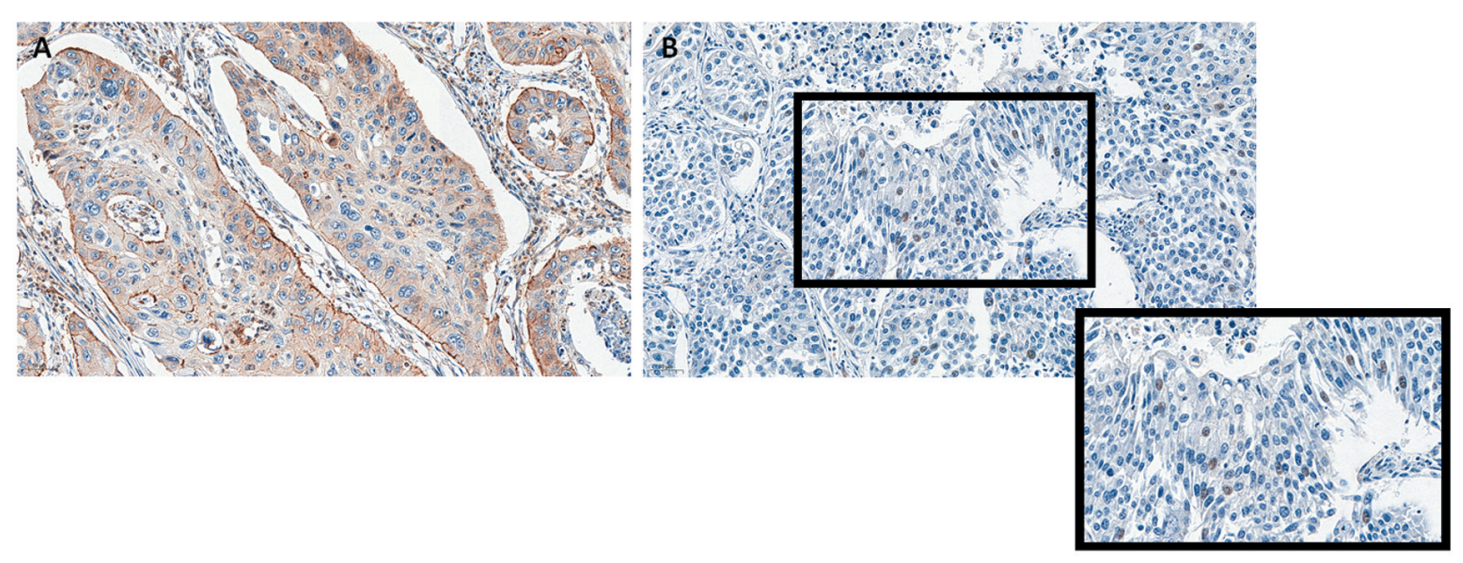

Figure 2. Cytoplasmic (A) and nuclear (B) localisation of zyxin in non-small cell lung cancer (property of the Department of Histology and Embryology, Wroclaw Medical University).

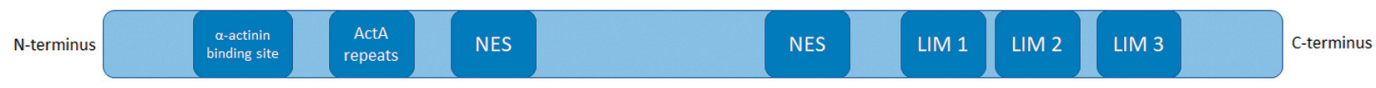

Figure 3. Schematic structure of zyxin [based on $(1,17)]$.

showed the role of Zyx in migration of normal murine mammary gland epithelial cells NMuMG (36). It was observed that under TGF $\beta$ treatment, significant increase in zyxin expression and translocation to stress fibres appeared, initiating the migration of the examined cells. It was also noticeable that an increase in zyxin expression under TGF $\beta$ stimulation is controlled by Twist1 (transcription factor) with an established role in EMT (36).

Other studies carried out on BT-20 breast cancer cell line presented that ZYX localisation in a cell can be probably related to breast cancer development (37). Lim and SH3 domain protein (LASP-1) is responsible for ZYX cellular 
distribution and plays a role in ZYX localisation to focal adhesions $(37,38)$. Studies performed on this cell line revealed that LASP-1 silencing leads to changes in ZYX localisation, inhibits proliferation, and decreases cell migration (37).

Lung cancer. Some research focused on the effect of ZYX in lung cancer pathogenesis suggests its suppressive role in carcinogenesis. The study of Hodgkinson et al. revealed that an increase in ZYX expression occurred after subjecting A549 lung cancer cell line to cyclooxygenase-2 (COX-2) specific inhibitor (29). COX-2 is an enzyme that catalyses the conversion of arachidonic acid to prostaglandins in response to inflammation $(39,40)$. It was shown that increased expression of COX-2 in non-small cell lung cancer (NSCLC) plays a significant role in lung cancer development through its effect on angiogenesis and immune response suppression in tumour cells $(40,41)$. The literature data show that carcinogenesis can be decelerated by the use of COX-2 inhibitors not only as single agents, but also in combined therapy (40-42). Therefore, an increased level of ZYX in response to the application of COX-2 inhibitor suggests the ability of ZYX to inhibit oncogenesis.

Stimulation of A549 cells with TGF $\beta$, a commonly recognized EMT inducer, resulted in increased ZYX expression (28). It was demonstrated that ZYX expression is dependent on SMAD3 (28), the effector molecule activated upon TGF $\beta$ treatment that takes part in gene expression regulation $(43,44)$. Furthermore, upon TGF $\beta$ stimulation, ZYX-silenced A549 cells exhibit increased expression of the integrin $\alpha 5$, i.e. a molecule responsible for cell adhesion and migration (28). An increased velocity of ZYX-deficient cells versus controls with unchanged ZYX expression was also noticed (28). In addition, significantly decreased expression of ZYX was detected in the K-ras ${ }^{L A 2}$ lung cancer mouse model (28). The above results suggest that ZYX might decelerate cancer progression through inhibition of cell migration.

The studies of Cadinu et al. confirm the suppressive function of ZYX in lung cancer development. Decreased ZYX expression was noticed in HCC4017 cells (NSCLC) in comparison to normal HBEC30KT cells (23). Also, lowered expression of other cytoskeleton-organising proteins was observed (23). Based on these results, a conclusion can be drawn that a change in cytoskeletal protein expression (including ZYX) may be cancer transformation-related.

Incubation of H1299 cells (NSCLC) with retinoic acid (RA) resulted in ZYX translocation from the cytoplasm into the nucleus (45). The use of retinoic acid in anticancer therapy is a very promising approach (46). After translocation into the nucleus, retinoic acid interacts with its receptor Retinoic Acid Receptor (RAR) that forms a complex with Retinoid X Receptor (RXR) (47). As a result, interaction with co-activators and transcription initiation can occur (47). It was demonstrated that after translocation into the nucleus, ZYX forms a complex with prostate tumour overexpressed 1 domain [PTOV1 domain, present in MED25 protein (48)] and CREB binding protein [CBP, transcription co-activator in RA signalling pathway (49)] (45). It inhibits CBP from interacting with RAR, thus resulting in a poor cytotoxic RA effect (45). This study presents partially the potential mechanism of the regulation of cellular response to ZYX.

Moreover, it was noticed that ZYX plasma concentration is significantly increased in patients diagnosed with NSCLC in comparison to healthy controls (50). Elevated ZYX levels were already detected in early stages of NSCLC, thus classifying it as a potential plasma marker of non-small cell lung cancer (50). In another study, the distribution of ZYX in serum and saliva exosomes was examined (51). Exosomes are exocrine vesicles that transport proteins, nucleic acids or lipids. It is believed that these vesicles take part in the communication between cells $(52,53)$. The content of ZYX in serum exosomes of patients with NSCLC was significantly lowered when compared to healthy controls (51). However, at present, the reasons for the observed discrepancies in ZYX levels in plasma and exosomes are difficult to be explained.

Melanoma. Elevated levels of ZYX were observed in melanoma cell lines (PM-WK, RPM-EP, RMP-MC, MM-AN) in comparison to normal melanocytes (6). In addition to this, melanoma cells showed shorter doubling time than normal cells (6). The study was extended to the incubation of cells with protein kinase C-activator - 12-O-tetradecanoylphorbol13-acetate (TPA) (6). Incubation of melanoma cells with TPA resulted in cell proliferation inhibition and in a decrease in ZYX expression (6). These results suggest that ZYX might affect cell proliferation and therefore, takes part in cancer progression (6).

This hypothesis was also confirmed by the study performed on A375 melanoma cell line (54), where it was shown that silencing Wilms' Tumour 1 (WT1, transcription factor) resulted in proliferation inhibition and decreased expression of ZYX and nestin (54). WT1 is a well-known regulator of cell growth and proliferation (55). The effect of WT1 on ZYX levels suggests that ZYX may participate in the regulation of proliferation through interacting with other factors (54). Similar observations were carried out by Michiels et al. (56) who examined the effect of Peroxisome Proliferator-Activated Receptor $\beta$ (PPAR $\beta$, transcription factor) on cancer cell proliferation. They showed that PPAR $\beta$ activation leads to a decrease in the expression of WT1, zyxin, and nestin, and to inhibition of cancer cell proliferation (56).

Colorectal cancer. The role of ZYX in the development and progression of colorectal cancer is still elusive, but existing studies show that this protein is an unfavourable prognostic factor. 
The study of Fukumoto et al. suggests that the formation of immature focal adhesions may be one of the mechanisms responsible for an increased invasion in DLD-1 colorectal cancer cell line. The lack of FA maturation results from the presence of alpha-actinin 4 inside these structures and the disturbed ZYX localisation (57). Alpha-actinin is a component of focal adhesions responsible for actin filament crosslinking (57). Four isoforms of alpha-actinin have been distinguished: 1, 2, 3, and 4 (57). The existing studies demonstrated that alpha-actinin 4 is related to cancer invasion (57). Disrupted binding of ZYX to alpha-actinin 4 was noticed, that may explain decreased stability of adhesions between cells and the extracellular matrix, and therefore increased cancer cell invasion (57). For comparison, the interaction of ZYX with alpha-actinin 1 was not disrupted, so the mature focal adhesions could appear (57).

Zhong et al. showed that ZYX expression was significantly higher in colorectal cancer lesions in comparison to normal tissues (58). The patients with tumours characterised by high ZYX expression had a shorter recurrence-free survival (58). In vitro experiments demonstrated that ZYX silencing in HCT116 colorectal cancer cell line caused decreased cell migration and invasion (58).

Moreover, ZYX fragments were detected in the serum of colorectal cancer patients. It suggests that zyxin can be a potential marker of colorectal cancer (59).

\section{The Role of Zyxin in the Development of Other Cancer Types}

The potential participation of ZYX in carcinogenesis has also been examined in other cancer types. The team of $\mathrm{Wu}$ et al. revealed the regulation of ZYX expression by miRNA-16 in Hep-2 laryngeal cancer cell line (60). The authors postulate that lowering ZYX expression with miRNA-16 increases the ability of Hep-2 cells to migrate (60). The function of miRNA-16-1 and its influence on ZYX expression was also examined in glioma (61). The levels of miRNA-16-1 in U251 and U87 glioma cell lines were significantly lower when compared to control brain tissue (61). It was observed that transfection of the glioma cell line with miRNA-16-1 leads to lower ZYX mRNA levels, decreased cell migration and invasion (61). The results of these experiments suggest that ZYX can have an impact on cancer cell invasion and therefore on the course of cancer.

The studies carried out on K562 chronic myeloid leukaemia cell line showed that silencing of ZYX with the use of specific shRNA resulted in lower levels of Bcl-2 and Bcl-XL, which are classified as antiapoptotic proteins (62). In addition, treatment of ZYX-silenced cells with Imatinib (Gleevec, BCR-ABL kinase inhibitor) led to an increase in apoptosis and to a decrease in cell growth in comparison to the control (62). These outcomes suggest that ZYX may exhibit an antiapoptotic function and thus, may induce cancer cell survival.

On the other hand, the suppressive role of zyxin was noticed in Ewing sarcoma (63). In the case of this cancer, Cerisano et al. demonstrated that ZYX takes part in CD99induced apoptosis (64). CD99 is a transmembrane protein, and its stimulation leads to an activation of caspaseindependent apoptosis (64). Treatment of Ewing sarcoma cells with anti-CD99 antibody (CD99 agonist) induced the expression of ZYX at mRNA and protein levels (64). In the following experiments, where ZYX was silenced with antisense oligonucleotides, partial inhibition of CD99induced apoptosis was found (64).

It is also supposed that ZYX takes part in cervical cancer development $(65,66)$. This hypothesis was proposed when the interaction of ZYX with E6 protein of human papilloma virus 6 (HPV6) was found (65). As it is commonly known, HPV is responsible, inter alia, for the genital warts and leads to cancer development $(16,65)$. It was demonstrated that the interaction of ZYX with a viral molecule causes its translocation into the nucleus. As a result, ZYX can influence transcription processes (65). These findings suggest that ZYX might promote cervical cancer progression through regulating expression of certain genes.

The contribution of ZYX to cervical cancer was also shown when the impact of thymosin $\beta 4$ on SiHa cancer cell line was studied (66). Thymosin $\beta 4$ is responsible for actin depolymerisation and its significant role in processes such as angiogenesis or metastasis was demonstrated (66). Over-expression of thymosin $\beta 4$ in $\mathrm{SiHa}$ cells turned out to increase ZYX expression (66). Similar effect was observed with cells incubated with exogenous thymosin $\beta 4$ (66). Moreover, ZYX expression was noticed to increase together with its translocation into the nucleus in the first hours of incubation. Afterwards, the protein returns to the cytoplasm (66). Based on these results, the authors suggest that $\mathrm{ZYX}$ and thymosin $\beta 4$ regulate the migratory properties of cells by coordinating actin polymerisation and depolymerisation, respectively (66). In addition, the authors suppose that $\mathrm{ZYX}$ might function as a transport molecule allowing thymosin $\beta 4$ to translocate into the nucleus (66). This could explain why ZYX transports into the nucleus and, after some time, returns to the cytoplasm and focal adhesions (66).

The oncogenic role of ZYX in hepatocellular carcinoma has also been examined. Sy et al. showed that ZYX expression is elevated in $33 \%$ of cancer cases, in comparison to control tissues (67). In vitro experiments demonstrated that ZYX silencing in Hep3B cancer cell line caused decreased cell migration and invasion (67).

Other studies have presented that lowered ZYX expression affects the level of the p53 protein and caspase activation 
(68). It was observed that UV radiation of ZYX-silenced HepG2 hepatocellular cancer cell line caused lower phosphorylation of p53 protein (specifically, serine at position 46) that resulted in inhibition of apoptosis and lack of caspase activation (68). Furthermore, elevated levels of ZYX fragments were detected in the sera of hepatocellular cancer patients (69). It suggests that ZYX may also be a potential marker of this cancer.

\section{Summary}

Based on the already published papers, the functions of ZYX in a cell are not only restricted to its presence in focal adhesions. As a result of translocation into the nucleus and the regulation of expression of certain genes, zyxin can take part in various cellular processes that occur in normal and cancer cells. The results of the presented studies suggest that ZYX may have a double effect on cancer progression, i.e. may act as an oncogene or tumour suppressor, depending on the cancer type. These discrepancies encourage researchers to further evaluate the role of zyxin in carcinogenesis.

\section{Conflicts of Interest}

The Authors declare that there are no conflicts of interest in relation to this study.

\section{Authors' Contributions}

Writing of the article and review of the literature were performed by AP. Review was performed by AG. Final review and final approval were performed by PD and MPO.

\section{Acknowledgements}

This article was written within the Wroclaw Medical University grant No. STM.A350.18.002.

\section{References}

1 Smith MA, Hoffman LM and Beckerle MC: LIM proteins in actin cytoskeleton mechanoresponse. Trends Cell Biol 24(10): 575-583, 2014. PMID: 24933506. DOI: 10.1016/j.tcb.2014.04.009

2 Bach I: The LIM domain: Regulation by association. Mech Dev 91(1-2): 5-17, 2000. PMID: 10704826. DOI: 10.1016/S09254773(99)00314-7

3 Velyvis A and Qin J: LIM Domain and its binding to target proteins. In: Zinc Finger Proteins: From Atomic Contact to Cellular Function. Molecular Biology Intelligence Unit. Iuchi S and Kuldell N (eds.). Landes Bioscience/Eurekah.com and Kluwer Academic/Plenum Publishers, pp. 99-105, 2005.

4 Macalma T, Otte J, Hensler ME, Bockholt SM, Louis HA, KalffSuske M, Grzeschik KH, Von der Ahe D and Beckerle MC: Molecular characterization of human zyxin. J Biol Chem 271(49): 31470-31478, 1996. PMID: 8940160. DOI: 10.1074/jbc.271. 49.31470
5 Zumbrunn J and Trueb B: Assignment of the ZYX gene for the LIM protein zyxin to human chromosome bands $7 \mathrm{q} 34-\mathrm{q} 35$ by in situ hybridization. Cytogenet Cell Genet 81(3-4): 283-284, 1998. PMID: 9730620. DOI: 10.1159/000015047

6 van der Gaag EJ, Leccia MT, Dekker SK, Jalbert NL, Amodeo DM and Byers HR: Role of zyxin in differential cell spreading and proliferation of melanoma cells and melanocytes. J Invest Dermatol 118(2): 246-254, 2002. PMID: 11841540. DOI: 10.1046/j.0022-202x.2001.01657.x

7 Hervy M, Hoffman L and Beckerle MC: From the membrane to the nucleus and back again: bifunctional focal adhesion proteins. Curr Opin Cell Biol 18(5): 524-532, 2006. PMID: 16908128. DOI: $10.1016 /$ j.ceb.2006.08.006

8 Choi Y-H, McNally BT and Igarashi P: Zyxin regulates migration of renal epithelial cells through activation of hepatocyte nuclear factor-1 $\beta$. Am J Physiol Renal Physiol 305(1): F100-F110, 2013. PMID: 23657850. DOI: 10.1152/ajprenal.00582.2012

9 Fife CM, McCarroll JA and Kavallaris M: Movers and shakers: Cell cytoskeleton in cancer metastasis. Br J Pharmacol 171(24): 5507-5523, 2014. PMID: 24665826. DOI: 10.1111/bph.12704

10 Ghosh S, Kollar B, Nahar T, Suresh Babu S, Wojtowicz A, Sticht C, Gretz N, Wagner AH, Korff T and Hecker M: Loss of the mechanotransducer zyxin promotes a synthetic phenotype of vascular smooth muscle cells. J Am Heart Assoc 4(6): e001712, 2015. PMID: 26071033. DOI: 10.1161/JAHA.114.001712

11 Sun Z, Huang S, Li Z and Meininger GA: Zyxin is involved in regulation of mechanotransduction in arteriole smooth muscle cells. Front Physiol 3: 472, 2012. PMID: 23267329. DOI: 10.3389/fphys.2012.00472

12 Hirata H, Tatsumi H and Sokabe M: Zyxin emerges as a key player in the mechanotransduction at cell adhesive structures. Commun Integr Biol 1(2): 192-195, 2008. PMID: 19513257. DOI: $10.4161 /$ cib.1.2.7001

13 Simiczyjew A, Malicka-Błaszkiewicz M and Nowak D: Functional diversification of cytoplasmic actin isoforms. Postepy Biochem 59(3): 285-294, 2013. PMID: 24364211.

14 Hoffman LM, Nix DA, Benson B, Boot-Hanford R, Gustafsson E, Jamora C, Menzies AS, Goh KL, Jensen CC, Gertler FB, Fuchs E, Fassler R and Beckerle MC: Targeted disruption of the murine zyxin gene. Mol Cell Biol 23(1): 70-79, 2003. PMID: 12482962. DOI: $10.1128 / \mathrm{mcb} .23 .1 .70-79.2003$

15 Hoffman LM, Jensen CC, Kloeker S, Wang CLA, Yoshigi M and Beckerle MC: Genetic ablation of zyxin causes Mena/VASP mislocalization, increased motility, and deficits in actin remodeling. J Cell Biol 172(5): 771-782, 2006. PMID: 16505170. DOI: $10.1083 / \mathrm{jcb} .200512115$

16 Kotb A, Hyndman ME and Patel TR: The role of zyxin in regulation of malignancies. Heliyon 4(7): e00695, 2018. PMID: 30094365. DOI: 10.1016/j.heliyon.2018.e00695

17 Hansen MDH and Kwiatkowski AV.: Control of actin dynamics by allosteric regulation of actin binding proteins. In: International Review of Cell and Molecular Biology. Volume 303. Jeon KW (ed.). Academic Press Elsevier, pp. 1-25, 2013.

18 Call GS, Chung JY, Davis JA, Price BD, Primavera TS, Thomson $\mathrm{NC}$, Wagner MV and Hansen MDH: Zyxin phosphorylation at serine 142 modulates the zyxin head-tail interaction to alter cellcell adhesion. Biochem Biophys Res Commun 404(3): 780-784, 2011. PMID: 21168386. DOI: 10.1016/j.bbrc.2010.12.058

19 Guo W and Wang Y: Retrograde fluxes of focal adhesion proteins in response to cell migration and mechanical signals. 
Mol Biol Cell 18(11): 4519-4527, 2007. PMID: 17804814. DOI: 10.1091/mbc.e07-06-0582

20 Yoshigi M, Hoffman LM, Jensen CC, Yost HJ and Beckerle MC: Mechanical force mobilizes zyxin from focal adhesions to actin filaments and regulates cytoskeletal reinforcement. J Cell Biol 171(2): 209-215, 2005. PMID: 16247023. DOI: $10.1083 /$ jcb.200 505018

21 Hervy M, Hoffman LM, Jensen CC, Smith M and Beckerle MC: The LIM protein zyxin binds CARP-1 and promotes apoptosis. Genes Cancer 1(5): 506-515, 2010. PMID: 20852740. DOI: $10.1177 / 1947601910376192$

22 Han X, Li P, Yang Z, Huang X, Wei G, Sun Y, Kang X, Hu X, Deng Q, Chen L, He A, Huo Y, Li D, Betzig E and Luo J: Zyxin regulates endothelial von Willebrand factor secretion by reorganizing actin filaments around exocytic granules. Nat Commun 8: 14639, 2017. PMID: 28256511. DOI: 10.1038/ncomms14639

23 Cadinu D, Hooda J, Alam MM, Balamurugan P, Henke RM and Zhang L: Comparative proteomic analysis reveals characteristic molecular changes accompanying the transformation of nonmalignant to cancer lung cells. EuPA Open Proteomics 3: 112, 2014. DOI: 10.1016/j.euprot.2014.01.001

24 Grunewald TGP, Kammerer U, Winkler C, Schindler D, Sickmann A, Honig A and Butt E: Overexpression of LASP-1 mediates migration and proliferation of human ovarian cancer cells and influences zyxin localisation. Br J Cancer 96(2): 296305, 2007. PMID: 17211471. DOI: 10.1038/sj.bjc.6603545

25 Ma B, Cheng H, Gao R, Mu C, Chen L, Wu S, Chen Q and Zhu Y: Zyxin-Siah2-Lats2 axis mediates cooperation between Hippo and TGF- $\beta$ signalling pathways. Nat Commun 7: 11123, 2016. PMID: 27030211. DOI: $10.1038 /$ ncomms 11123

26 Zhao HF, Wang J, Jiang HR, Chen ZP and To SST: PI3K p110 $\beta$ isoform synergizes with JNK in the regulation of glioblastoma cell proliferation and migration through Akt and FAK inhibition. J Exp Clin Cancer Res 35: 78, 2016. PMID: 27176481. DOI: 10.1186/s 13046-016-0356-5

27 Yamamura M, Noguchi K, Nakano Y, Segawa E, Zushi Y, Takaoka $\mathrm{K}$, Kishimoto H, Hashimoto-Tamaoki T and Urade M: Functional analysis of Zyxin in cell migration and invasive potential of oral squamous cell carcinoma cells. Int J Oncol 42(3): 873-880, 2013. PMID: 23292068. DOI: 10.3892/ijo.2013.1761

28 Mise N, Savai R, Yu H, Schwarz J, Kaminski N and Eickelberg $\mathrm{O}$ : Zyxin is a transforming growth factor-beta (TGFbeta)/Smad3 target gene that regulates lung cancer cell motility via integrin alpha-5 beta-1. J Biol Chem 287(37): 31393-31405, 2012. PMID: 22778267. DOI: 10.1074/jbc.M112.357624

29 Hodgkinson VC, ElFadl D, Drew PJ, Lind MJ and Cawkwell L: Repeatedly identified differentially expressed proteins (RIDEPs) from antibody microarray proteomic analysis. J Proteomics 74(5): 698-703, 2011. PMID: 21338725. DOI: 10.1016/j.jprot.2011. 02.014

30 Hodgkinson VC, ElFadl D, Agarwal V, Garimella V, Russell C, Long ED, Fox JN, McManus PL, Mahapatra TK, Kneeshaw PJ, Drew PJ, Lind MJ and Cawkwell L: Proteomic identification of predictive biomarkers of resistance to neoadjuvant chemotherapy in luminal breast cancer: A possible role for 14-3-3 theta / tau and tBID? J Proteomics 75(4): 1276-1283, 2012. PMID: 22115752. DOI: 10.1016/j.jprot.2011.11.005

31 Harvey KF, Zhang X and Thomas DM: The Hippo pathway and human cancer. Nat Rev Cancer 13(4): 246-257, 2013. PMID: 23467301. DOI: $10.1038 / \mathrm{nrc} 3458$
32 Diepenbruck M, Waldmeier L, Ivanek R, Berninger P, Arnold P, van Nimwegen E and Christofori G: Tead2 expression levels control the subcellular distribution of Yap and Taz, zyxin expression and epithelial-mesenchymal transition. J Cell Sci 127: 1523-1536, 2014. PMID: 24554433. DOI: 10.1242/jcs.139865

33 Lei QY, Zhang H, Zhao B, Zha ZY, Bai F, Pei XH, Zhao S, Xiong Y and Guan KL: TAZ promotes cell proliferation and epithelial-mesenchymal transition and is inhibited by the hippo pathway. Mol Cell Biol 28(7): 2426-2436, 2008. PMID: 18227151. DOI: 10.1128/MCB.01874-07

34 Zhao B, Ye X, Yu J, Li L, Li W, Li S, Yu J, Lin JD, Wang CY, Chinnaiyan AM, Lai ZC and Guan KL: TEAD mediates YAPdependent gene induction and growth control. Genes Dev 22: 1962-1971, 2008. PMID: 18579750. DOI: 10.1101/gad.1664408

35 Zhang H, Liu CY, Zha ZY, Zhao B, Yao J, Zhao S, Xiong Y, Lei QY and Guan KL: TEAD transcription factors mediate the function of TAZ in cell growth and epithelial-mesenchymal transition. J Biol Chem 284(20): 13355-13362, 2009. PMID: 19324877. DOI: $10.1074 /$ jbc.M900843200

36 Mori M, Nakagami H, Koibuchi N, Miura K, Takami Y, Koriyama H, Hayashi H, Sabe H, Mochizuki N, Morishita R and Kaneda Y: Zyxin mediates actin fiber reorganization in epithelial-mesenchymal transition and contributes to endocardial morphogenesis. Mol Biol Cell 20(13): 3115-3124, 2009. PMID: 19439447. DOI: 10.1091/mbc.e09-01-0046

37 Grunewald TGP, Kammerer U, Schulze E, Schindler D, Honig A, Zimmer M and Butt E: Silencing of LASP-1 influences zyxin localization, inhibits proliferation and reduces migration in breast cancer cells. Exp Cell Res 312(7): 974-982, 2006. PMID 16430883. DOI: 10.1016/j.yexcr.2005.12.016

38 Orth MF, Cazes A, Butt E and Grunewald TGP: An update on the LIM and SH3 domain protein 1 (LASP1): A versatile structural, signaling, and biomarker protein. Oncotarget 6(1): 2642, 2015. PMID: 25622104. DOI: 10.18632/oncotarget.3083

39 O'Kane SL, Eagle GL, Greenman J, Lind MJ and Cawkwell L: COX-2 specific inhibitors enhance the cytotoxic effects of pemetrexed in mesothelioma cell lines. Lung Cancer 67(2): 160165, 2010. PMID: 19450893. DOI: 10.1016/j.lungcan.2009.04.008

40 Martinez-Marti A, Navarro A and Felip E: COX-2 inhibitors in NSCLC: Never-ending story or misplaced? Transl Lung Cancer Res 7: S191-S194, 2018. PMID: 30393598. DOI: 10.21037/ tlcr.2018.04.17

41 Sandler $\mathrm{AB}$ and Dubinett SM: COX-2 inhibition and lung cancer. Semin Oncol 31: 45-52, 2004. PMID: 15179623. DOI: 10.1053/j.seminoncol.2004.03.045

42 Hohenforst-Schmidt W, Domvri K, Zogas N, Zarogoulidis P, Petanidis S, Kioseoglou E, Zachariadis G, Kakolyris S, Porpodis $\mathrm{K}$, Gaga M, Huang H, Kontakiotis T and Zarogoulidis K: COX2 inhibitors, a potential synergistic effect with antineoplastic drugs in lung cancer. Oncomedicine 2: 28-36, 2017. DOI: 10.7150/oncm. 17020

43 Derynck R and Zhang YE: Smad-dependent and Smad-independent pathways in TGF-beta family signalling. Nature 425(6958): $577-$ 584, 2003. PMID: 14534577. DOI: 10.1038/nature02006

44 Finnson KW, McLean S, Di Guglielmo GM and Philip A: Dynamics of transforming growth factor beta signaling in wound healing and scarring. Adv Wound Care 2(5): 195-214, 2013. PMID: 24527343. DOI: 10.1089/wound.2013.0429

45 Youn H, Kim EJ and Um SJ: Zyxin cooperates with PTOV1 to confer retinoic acid resistance by repressing RAR activity. 
Cancer Lett 331(2): 192-199, 2013. PMID: 23321499. DOI: 10.1016/j.canlet.2012.12.019

46 Zito G, Naselli F, Saieva L, Raimondo S, Calabrese G, Guzzardo C, Forte S, Rolfo C, Parenti R and Alessandro R: Retinoic acid affects lung adenocarcinoma growth by inducing differentiation via GATA6 activation and EGFR and Wnt inhibition. Sci Rep 7(1): 4770, 2017. PMID: 28684780. DOI: 10.1038/s41598-01705047-z

47 Gutierrez-Mazariegos J, Schubert M and Laudet V: Evolution of retinoic acid receptors and retinoic acid signaling. In: The Biochemistry of Retinoic Acid Receptors I: Structure, Activation, and Function at the Molecular Level. Subcellular Biochemistry, vol 70. Asson-Batres MA and Rochette-Egly C (eds.). Dordrecht, Springer, pp. 55-73, 2014.

48 Landrieu I, Verger A, Baert JL, Rucktooa P, Cantrelle F-X, Dewitte F, Ferreira E, Lens Z, Villeret V and Monté D: Characterization of ERM transactivation domain binding to the ACID/PTOV domain of the Mediator subunit MED25. Nucleic Acids Res 43(14): 71107121, 2015. PMID: 26130716. DOI: 10.1093/nar/gkv650

49 Piskunov A, Al Tanoury Z and Rochette-Egly C: Nuclear and extra-nuclear effects of retinoid acid receptors: How they are interconnected. In: The Biochemistry of Retinoic Acid Receptors I: Structure, Activation, and Function at the Molecular Level. Subcellular Biochemistry, vol 70. Asson-Batres MA and Rochette-Egly C (eds.). Dordrecht, Springer, pp. 103-127, 2014.

50 Kim YJ, Sertamo K, Pierrard M-A, Mesmin C, Kim SY, Schlesser M, Berchem G and Domon B: Verification of the biomarker candidates for non-small-cell lung cancer using a targeted proteomics approach. J Proteome Res 14(3): 1412-1419, 2015. PMID: 25597550. DOI: 10.1021/pr5010828

51 Sun Y, Liu S, Qiao Z, Shang Z, Xia Z, Niu X, Qian L, Zhang Y, Fan L, Cao CX and Xiao H: Systematic comparison of exosomal proteomes from human saliva and serum for the detection of lung cancer. Anal Chim Acta 982: 84-95, 2017. PMID: 28734369. DOI: 10.1016/j.aca.2017.06.005

52 Théry C, Zitvogel L and Amigorena S: Exosomes: Composition, biogenesis and function. Nat Rev Immunol 2(8): 569-579, 2002. PMID: 12154376. DOI: 10.1038/nri855

53 Mashouri L, Yousefi H, Aref AR, Ahadi AM, Molaei F and Alahari SK: Exosomes: Composition, biogenesis, and mechanisms in cancer metastasis and drug resistance. Mol Cancer 18(1): 75, 2019. PMID: 30940145. DOI: 10.1186/s12943-019-0991-5

54 Wagner N, Panelos J, Massi D and Wagner KD: The Wilms ' tumor suppressor WT1 is associated with melanoma proliferation. Pflügers Arch - Eur J Physiol 455(5): 839-847, 2008. PMID: 17912546. DOI: 10.1007/s00424-007-0340-1

55 Bielińska E, Matiakowska K and Haus O: Heterogeneity of human WT1 gene. Postepy Hig Med Dosw 71: 595-601, 2017. PMID: 28791954. DOI: 10.5604/01.3001.0010.3840

56 Michiels J-F, Perrin C, Leccia N, Massi D, Grimaldi P and Wagner N: PPARß activation inhibits melanoma cell proliferation involving repression of the Wilms' tumour suppressor WT1. Pflügers Arch - Eur J Physiol 459(5): 689-703, 2010. PMID: 20066433. DOI: 10.1007/s00424-009-0776-6

57 Fukumoto M, Kurisu S, Yamada T and Takenawa T: $\alpha$-Actinin4 enhances colorectal cancer cell invasion by suppressing focal adhesion maturation. PLoS One 10(4): e0120616, 2015. PMID: 25860875. DOI: 10.1371/journal.pone.0120616

58 Zhong C, Yu J, Li D, Jiang K, Tang Y, Yang M, Shen H, Fang $\mathrm{X}$, Ding K, Zheng S and Yuan Y: Zyxin as a potential cancer prognostic marker promotes the proliferation and metastasis of colorectal cancer cells. J Cell Physiol 234(9): 15775-15789, 2019. PMID: 30697742 . DOI: $10.1002 /$ jcp. 28236

59 Kawashima Y, Fukutomi T, Tomonaga T, Takahashi H, Nomura F, Maeda T and Kodera Y: High-yield peptide-extraction method for the discovery of subnanomolar biomarkers from small serum samples. J Proteome Res 9(4): 1694-1705, 2010. PMID: 20184378. DOI: $10.1021 /$ pr9008018

$60 \mathrm{Wu} \mathrm{H}$, Liu T, Wang R, Tian S, Liu M, Li X and Tang H: MicroRNA-16 targets zyxin and promotes cell motility in human laryngeal carcinoma cell line HEp-2. IUBMB Life 63(2): 101108, 2011. PMID: 21360639. DOI: 10.1002/iub.417

61 Li X, Ling N, Bai Y, Dong W, Hui G-Z, Liu D, Zhao J and Hu $\mathrm{J}$ : MiR-16-1 plays a role in reducing migration and invasion of glioma cells. Anat Rec 296(3): 427-432, 2013. PMID: 23175429. DOI: 10.1002/ar.22626

62 Bernusso VA, Machado-Neto JA, Pericole F V., Vieira KP, Duarte ASS, Traina F, Hansen MD, Olalla Saad ST and Barcellos KSA: Imatinib restores VASP activity and its interaction with Zyxin in BCR-ABL leukemic cells. Biochim Biophys Acta 1853(2): 388-395, 2015. PMID: 25450971. DOI: 10.1016/j.bbamcr.2014.11.008

63 Amsellem V, Kryszke M-H, Hervy M, Subra F, Athman R, Leh $\mathrm{H}$, Brachet-Ducos $\mathrm{C}$ and Auclair C: The actin cytoskeletonassociated protein zyxin acts as a tumor suppressor in Ewing tumor cells. Exp Cell Res 304(2): 443-456, 2005. PMID: 15748890. DOI: 10.1016/j.yexcr.2004.10.035

64 Cerisano V, Aalto Y, Perdichizzi S, Bernard G, Manara MC, Benini S, Cenacchi G, Preda P, Lattanzi G, Nagy B, Knuutila S, Colombo MP, Bernard A, Picci P and Scotlandi K: Molecular mechanisms of CD99-induced caspase-independent cell death and cell-cell adhesion in Ewing's sarcoma cells: actin and zyxin as key intracellular mediators. Oncogene 23(33): 5664-5674, 2004. PMID: 15184883. DOI: 10.1038/sj.onc.1207741

65 Degenhardt YY and Silverstein S: Interaction of zyxin, a focal adhesion protein, with the E6 protein from human papillomavirus type 6 results in its nuclear translocation. J Virol 75(23): 11791-11802, 2001. PMID: 11689660. DOI: 10.1128/JVI.75.23.11791-11802.2001

66 Moon H-S, Even-Ram S, Kleinman HK and Cha H-J: Zyxin is upregulated in the nucleus by thymosin $\beta 4$ in SiHa cells. Exp Cell Res 312(17): 3425-3431, 2006. PMID: 16956606. DOI: 10.1016/j.yexcr.2006.07.021

67 Sy SM-H, Lai PB-S, Pang E, Wong NL-Y, To K-F, Johnson PJ and Wong N: Novel identification of zyxin upregulations in the motile phenotype of hepatocellular carcinoma. Mod Pathol 19(8): 11081116, 2006. PMID: 16680155. DOI: 10.1038/modpathol.3800626

68 Crone J, Glas C, Schultheiss K, Moehlenbrink J, KrieghoffHenning E and Hofmann TG: Zyxin is a critical regulator of the apoptotic HIPK2-p53 signaling axis. Cancer Res 71(6): 2350-2359, 2011. PMID: 21248071. DOI: 10.1158/0008-5472.CAN-10-3486

69 An Y, Bekesova S, Edwards N and Goldman R: Peptides in low molecular weight fraction of serum associated with hepatocellular carcinoma. Dis Markers 29(1): 11-20, 2010. PMID: 20826913. DOI: 10.3233/DMA-2010-0721

Received September 23, 2020

Revised October 2, 2020

Accepted October 5, 2020 